\title{
Maternal and Perinatal Outcomes Among Women Underwent Second-Stage Versus First-Stage Caesarean Delivery at Ibrahim Malik Hospital in Sudan
}

\author{
Azza Jaafar Bashir ${ }^{1}$, Rihab Jaafar Ibrahim ${ }^{2}$, Yassir Ahmed Mohammed Elhassan ${ }^{3}$, Awad Ali M Alawad ${ }^{4}$ and \\ Siddig Omer M Handady ${ }^{2 *}$ \\ ${ }^{1}$ Department of Obstetrical and Gynecology, Omdurman Maternity hospital, Sudan
}

${ }^{2}$ Department of Obstetrical and Gynecology, Ibrahim Malik hospital, Sudan

${ }^{3}$ Department of Anatomy, University of Kordofan, Sudan

${ }^{4}$ Faculties of Medicine, University of Medical Sciences and Technology, Sudan

*Corresponding author: Siddig Omer M Handady, Department of Obstetrical \& Gynecology, Ibrahim Malik hospital, Khartoum, Sudan.
Received Date: October 29, 2018

Published Date: November 26, 2018

\begin{abstract}
Background: Second-stage caesarean is more technically difficult due to deep engagement of the fetal head, and this is associated with increased risk of maternal morbidity such as (surgical injuries and intra-operative hemorrhage) as well as fetal morbidity such as (hypoxia and fetal injury).

Objective: To determine maternal and perinatal outcome associated with caesarean sections performed in the second versus first stages of labor.

Methodology: It was observational cross sectional -hospital based study carried out in Ibrahim Malik Hospital in Khartoum State, Sudan, in the period from October 2015 to October 2016. Six hundred women were enrolled in this study. 200 women were undergoing second stage caesarean section for variable indications, while 400 women underwent first stage caesarean section.

Results: We found that women who underwent caesarean delivery in the second stage of labor had greater risk of maternal morbidity than those who underwent caesarean delivery in the first stage of labor. The rate of Bleeding $>1000 \mathrm{ml} \mathrm{(16.0 \%} \mathrm{vs.} 0.7 .5 \%)$, extension of the uterine incision ( $20.5 \%$ vs. $6.25 \%$ ), bladder injury ( $4.0 \%$ vs. $1.25 \%)$. The rate of fetal injury during delivery ( $5.5 \%$ vs. $2.0 \%$ ), FSB ( $4.5 \%$ vs. $2.25 \%$ ), admission to the neonatal intensive care unit ( $18.0 \%$ vs. $12.5 \%$ ), neonatal sepsis ( $3.5 \%$ vs. $1.5 \%)$ and early neo- natal death $(2.0 \%$ vs. $2.25 \%)$.

Conclusion: Intra operative bleeding, adhesion, bladder injury, caesarian hysterectomy, perinatal asphyxia, FSB, birth trauma, NICU admission and low Apgar score were most morbidity related to $2^{\text {nd }}$ stage cesarean delivery.
\end{abstract}

Keywords: $2^{\text {nd }}$ stage C/S, 1st stage C/S, Maternal, Fetal, Outcome, Comparison

\section{Introduction}

Caesarean section is the delivery of the fetus, placenta and membranes through an incision in the abdominal wall and uterine walls. The first performed caesarean section is known as primary caesarean section, subsequent procedure, known as repeat caesarean section [1].

Classically caesarean section is divided in two types; elective and emergency. Emergency caesarean section can be performed during first or second stage of labor.
Second stage caesarean section is an emergency caesarean section performed when the patient is fully dilated, i.e. when the uterine cervix is $10 \mathrm{~cm}$ dilated.

Decision making surrounding cesarean section in the second stage of labor is one of the greatest challenges in current obstetric practice. The rates of cesarean sections have risen steadily in the past two decades and may be associated with a disproportionate rise in second stage of cesarean section due to a decline in the use 
of instrumental deliveries [2]. Cesarean section at full cervical dilatation with an impacted fetal head can be technically difficult and is associated with increased trauma to the lower uterine segment and adjacent structures, as well as increased hemorrhage and infection [3]. When compared with cesarean deliveries in the first stage of labor, cesarean deliveries in the second stage have been associated with longer surgery time, increased postoperative fever [4], maternal intra operative trauma [5] and composite maternal morbidity [6].

The present paper focus to compare the maternal and perinatal morbidity associated with caesarean sections performed in the second versus first stages of labor.

\section{Materials and Methods}

It was observational cross sectional -hospital based study carried out in Ibrahim Malik Hospital in Khartoum State, Sudan, in the period from October 2015 to October 2016. Six hundred women were enrolled in this study. Two hundred women were undergoing second stage caesarean section for variable indications, while 400 women underwent first stage caesarean section. Lower segment approach technique was used (Pfannenstiel) incisions were used on all patients. Maternal characteristics, such as maternal age, body mass index and gestational age were noted. Additionally, the length of the active phase of labor, indication for caesarean delivery, type of anesthesia, time from skin incision to delivery and total operation time were noted.

Maternal morbidity outcome variables were length of hospital stay, wound infection, estimated and excessive blood loss (1, 000 $\mathrm{ml}$ ), need for blood transfusion and puerperal infection. Intraoperative complications, including extension of a uterine incision, bladder injury, or requirement of hysterectomy were also noted. Neonatal outcome indicators included birth weight (g), Apgar score of the newborn at $5 \mathrm{~min}$, rates of fetal injury and septicemia, transport requirement of the infant to the neonatal intensive care unit and neonatal death. Outcomes for caesarean delivery in the second stage of labor were compared with outcomes of women undergoing caesarean delivery in the first stage.

Data was entered into SPSS version 22 and analyzed accordingly. The quantitative variables were presented in mean and standard deviation and qualitative variables were presented in frequency and percentages. Important summary statistics were obtained, and associations were examined using chi-square test. Significance level of 0.05 (i.e. $\mathrm{P}<0.05$ ) was used to determine the significance of associations being examined.

Ethical clearance and approval for conducting this research was obtained from the general manager of the hospital and informed verbal consent was obtained from every respondent who agreed to participate in the study. Of course, the respondent informed that the study is not associated with experimental or therapeutic intervention while information was collected from her.

\section{Results}

During the study period 8,245 deliveries occurred at Ibrahim Malik Hospital, Sudan. The current study showed the rate of $2^{\text {nd }}$ stage C/S was (2.4\%) 200/8245 (200 number of women deliver through $2^{\text {nd }}$ stage $\mathrm{C} / \mathrm{S}$ and 8245 were total number of deliveries during the whole study period). The caesarean delivery rate was $26.9 \%$ (2217/8245) (2217 number of women delivers through C/S and 8245 were total number of deliveries during the whole study period).

Table 1 The mean age of women in $2^{\text {nd }}$ stage was $27.2 \pm 3.1$ years; and $26.5 \pm 5.2$ years in 1st stage respectively, the mean parity of women in the $2^{\text {nd }}$ stage was $1.3 \pm 6.1$; while that in the 1 st stage was $2.3 \pm 3.4$. Regarding gestational age at presentation, the average gestation age in the $2^{\text {nd }}$ stage was $38.4+1.2$ weeks; while that in the $1^{\text {st }}$ stage was $38.1+1.5$ weeks. The average total operation time were significantly greater in the second-stage group $(49.23 \pm 1.13 \mathrm{~min})$ than in the first-stage group (35.16 $1.22 \mathrm{~min}$; p value 0.00 ).

Table 1: Shows the nonparametric correlation between the two groups regarding demographic data.

\begin{tabular}{|c|c|c|c|c|c|}
\hline \multirow[b]{2}{*}{ Age in years } & \multicolumn{2}{|c|}{$2^{\text {nd }}$ Stage } & \multicolumn{2}{|c|}{$1^{\text {st }}$ Stage } & \multirow[b]{2}{*}{$P$ value } \\
\hline & Count & $\%$ & Count & $\%$ & \\
\hline$<20$ & 14 & $7.00 \%$ & 44 & $11.00 \%$ & \multirow{5}{*}{0.136} \\
\hline $20-30$ & 117 & $58.50 \%$ & 221 & $55.25 \%$ & \\
\hline $31-40$ & 50 & $25.00 \%$ & 102 & $25.50 \%$ & \\
\hline$>40$ & 19 & $9.50 \%$ & 33 & $08.25 \%$ & \\
\hline Total & 200 & $100.00 \%$ & 400 & $100.00 \%$ & \\
\hline \multicolumn{5}{|c|}{ BMI $\left(\mathrm{kg} / \mathrm{m}^{2}\right)$} & \multirow{6}{*}{0.17} \\
\hline$<20$ & 21 & $10.5 \%$ & 56 & $14.00 \%$ & \\
\hline $20-25$ & 24 & $12.0 \%$ & 67 & $16.75 \%$ & \\
\hline $26-30$ & 102 & $51.0 \%$ & 186 & $46.50 \%$ & \\
\hline$>30$ & 53 & $26.5 \%$ & 91 & $22.75 \%$ & \\
\hline Total & 200 & $100.0 \%$ & 400 & $100.00 \%$ & \\
\hline \multicolumn{5}{|c|}{ GA in weeks } & \multirow{5}{*}{0.13} \\
\hline $37-39$ & 113 & $56.5 \%$ & 202 & $50.50 \%$ & \\
\hline $40-42$ & 72 & $36.0 \%$ & 104 & $26.00 \%$ & \\
\hline$>42$ & 15 & $07.5 \%$ & 94 & $23.50 \%$ & \\
\hline Total & 200 & $100.0 \%$ & 400 & $100.00 \%$ & \\
\hline \multicolumn{5}{|c|}{ Party } & \multirow{5}{*}{$0.00^{*}$} \\
\hline$P G$ & 137 & $68.5 \%$ & 198 & $49.50 \%$ & \\
\hline Multipara & 54 & $27.0 \%$ & 127 & $31.75 \%$ & \\
\hline $\begin{array}{c}\text { Grandmulti- } \\
\text { para }\end{array}$ & 09 & $04.5 \%$ & 75 & $18.75 \%$ & \\
\hline Total & 200 & $100.0 \%$ & 400 & $100.00 \%$ & \\
\hline \multicolumn{5}{|c|}{ Status of booking } & \multirow{4}{*}{$0.000^{*}$} \\
\hline Booked & 155 & $77.5 \%$ & 308 & $77.00 \%$ & \\
\hline Un booked & 45 & $22.5 \%$ & 92 & $23.00 \%$ & \\
\hline Total & 200 & $100.0 \%$ & 400 & $100.00 \%$ & \\
\hline \multicolumn{4}{|c|}{ Total operation time (min) } & & \\
\hline $30-40$ & 24 & $12.0 \%$ & 208 & $52.0 \%$ & \multirow{4}{*}{$0.000^{*}$} \\
\hline $41-50$ & 136 & $68.0 \%$ & 168 & $42.0 \%$ & \\
\hline$>50$ & 40 & $20.0 \%$ & 24 & $06.0 \%$ & \\
\hline Total & 200 & $100.0 \%$ & 400 & $100.0 \%$ & \\
\hline
\end{tabular}

*Statistically significant at 0.05 level. 
Table 2: Shows the nonparametric correlation between the two group regarding maternal and fetal outcome.

\begin{tabular}{|c|c|c|c|c|c|}
\hline & $\begin{array}{c}\text { 2nd } \\
\text { Stage }\end{array}$ & \multicolumn{1}{|c|}{$\begin{array}{c}\text { 1st } \\
\text { Stage }\end{array}$} & \multicolumn{1}{|c|}{$\begin{array}{c}\text { P } \\
\text { value }\end{array}$} \\
\hline Count & $\%$ & Count & $\%$ & \\
\hline Maternal complications Intra operative \\
\hline Bleeding >1000 ml & 32 & $16.0 \%$ & 30 & $7.50 \%$ & $0.00^{*}$ \\
\hline Injury to bladder & 8 & $4.0 \%$ & 05 & $1.25 \%$ & $0.02^{*}$ \\
\hline Injury to bowel & 03 & $1.5 \%$ & 01 & $0.25 \%$ & $0.01^{*}$ \\
\hline Injury to fetus & 11 & $5.5 \%$ & 8 & $2.00 \%$ & $0.00^{*}$ \\
\hline Anesthetic & 14 & $7.00 \%$ & 18 & $4.50 \%$ & $0.04^{*}$ \\
\hline Complications & 41 & $20.50 \%$ & 25 & $6.25 \%$ & $0.03^{*}$ \\
\hline $\begin{array}{c}\text { Extending tears } \\
\text { hysterectomy }\end{array}$ & 02 & $1.00 \%$ & 01 & $0.25 \%$ & $0.02^{*}$ \\
\hline
\end{tabular}

Maternal complications post-operative

\begin{tabular}{|c|c|c|c|c|c|}
\hline PPH & 27 & $13.50 \%$ & 31 & $7.75 \%$ & $0.02^{*}$ \\
\hline Paralytic ileus & 7 & $3.50 \%$ & 06 & $1.5 \%$ & $0.04^{*}$ \\
\hline Infection & 19 & $9.50 \%$ & 10 & $2.5 \%$ & $0.00^{*}$ \\
\hline Pyrexia & 21 & $10.50 \%$ & 17 & $4.25 \%$ & $0.01^{*}$ \\
\hline Wound dehiscence & 02 & $1.00 \%$ & 00 & $0.0 \%$ & $0.04^{*}$ \\
\hline
\end{tabular}

\begin{tabular}{|c|c|c|c|c|c|}
\hline $\begin{array}{c}\text { Neonatal out come } \\
\text { Low 5min Apgar } \\
\text { score }\end{array}$ & 11 & $05.5 \%$ & 09 & $2.25 \%$ & $0.03^{*}$ \\
\hline FSB & 09 & $04.5 \%$ & 09 & $2.25 \%$ & $0.00^{*}$ \\
\hline $\begin{array}{c}\text { Early neonatal } \\
\text { death }\end{array}$ & 04 & $02.0 \%$ & 7 & $1.75 \%$ & 0.14 \\
\hline Neonatal sepsis & 07 & $03.5 \%$ & 06 & $1.50 \%$ & $0.003^{*}$ \\
\hline NICU admission & 36 & $18.0 \%$ & 50 & $12.50 \%$ & $0.00^{*}$ \\
\hline
\end{tabular}

Fetal weight

\begin{tabular}{|c|c|c|c|c|c|}
\hline$<2.5 \mathrm{Kg}$ & 02 & $1.00 \%$ & 26 & $6.50 \%$ & \\
\cline { 1 - 5 } $2.5-3.5 \mathrm{Kg}$ & 115 & $57.50 \%$ & 269 & $67.25 \%$ & \multirow{2}{*}{$0.01^{*}$} \\
\cline { 1 - 5 }$>3.5 \mathrm{Kg}$ & 83 & $41.50 \%$ & 105 & $26.25 \%$ & \\
\cline { 1 - 5 } Total & 200 & $100.00 \%$ & 400 & $100.00 \%$ & \\
\hline
\end{tabular}

Apgar score

\begin{tabular}{|c|c|c|c|c|c|}
\hline$<5$ & 15 & $07.5 \%$ & 08 & $2.00 \%$ & \\
\cline { 1 - 4 } $5-9$ & 49 & $24.5 \%$ & 101 & $25.25 \%$ & \multirow{2}{*}{$0.02 *$} \\
\cline { 1 - 4 }$>$ T9 9 & 136 & $68.0 \%$ & 291 & $72.75 \%$ & \\
\cline { 1 - 4 } Total & 200 & $100.0 \%$ & 400 & $100.00 \%$ & \\
\cline { 1 - 3 } & & & & &
\end{tabular}

Hospital stay (days)

\begin{tabular}{|c|c|c|c|c|c|}
\hline $1-3$ days & 82 & $41.0 \%$ & 286 & $71.50 \%$ & \\
\cline { 1 - 5 }$>$ >3 days & 118 & $59.0 \%$ & 114 & $28.50 \%$ & \multirow{2}{*}{$0.01^{*}$} \\
\cline { 1 - 5 } Total & 200 & $100.0 \%$ & 400 & $100.00 \%$ & \\
\hline
\end{tabular}

*Statistically significant at 0.05 level.

Table 2 Shows the nonparametric correlation between the two groups regarding maternal and fetal outcome. We found that women who underwent caesarean delivery in the second stage of labor had greater risk of maternal morbidity than those who underwent caesarean delivery in the first stage of labor. The rate of bleeding $>1000 \mathrm{ml}$ ( $16.0 \%$ vs. $7.5 \%$ ), extension of the uterine incision (20.5\% vs. $6.25 \%$ ), bladder injury ( $4.0 \%$ vs. $1.25 \%)$ and Injury to bowel ( $1.5 \%$ vs. $0.25 \%$ ), were significantly lower in the first-stage group than in the second-stage group. Two (1.0\%) patients underwent a caesarean hysterectomy in the second-stage group, whereas only one patient $(0.025 \%)$ in the first-stage group underwent caesarean hysterectomy; this difference was significant different ( $p$ value 0.02 ). The rate of fetal injury during delivery ( $5.5 \%$ vs. $2.0 \%$ ), FSB ( $4.5 \%$ vs. $2.25 \%$ ), admission to the neonatal intensive care unit (18.0\% vs. $12.5 \%)$, neonatal sepsis $(3.5 \%$ vs. $1.5 \%)$ and early neo- natal death (2.0\% vs. $1.75 \%)$.

\section{Discussion}

Caesarean sections during the second stage are increasing in prevalence and are associated with significant long-term psychological and physical maternal morbidity. It has significant problems that require skill and knowledge to limit potential adverse events. It likely to remain a frequent problem for obstetricians in the foreseeable future with continuing pressures to reduce elective CS rates.

The present study demonstrated that women who underwent caesarean delivery in the second stage of labor had significantly higher maternal and neonatal morbidity than did women who underwent caesarean delivery in the first stage of labor.

Allen VM and his colleagues revealed, that caesarean delivery in second stage of labor is associated with increased maternal morbidity compared with caesarean delivery in the first stage of labor [7].

Also, Rabiu, et al. [8], found that women who had caesarean deliveries performed in the second stage had longer operative times, higher blood loss, more cases of intra operative trauma, primary postpartum hemorrhage, blood transfusion, relook laparotomy, hysterectomy, postoperative pyrexia, wound infection and a longer hospital stay (all $\mathrm{p}<0.05$ ).

Our finding is correlate with Allen VM [7] and comparable with Rabiu, et al. [8]. However, contrary to our findings, Allen et al. [4], did not find any differences in the rates of blood transfusion requirements, hysterectomy or postpartum hemorrhage.

Neonatal outcome was controversial in previous studies, particularly the risk of fetal asphyxia. Alexander JM [5] and SeloOjeme et al. [9] found no difference in the risk of fetal asphyxia.

However, the current study revealed that caesarean delivery performed during the second stage of labor increases the incidence of fetal injury, septicemia, admission to the neonatal intensive care unit and fetal death due to fetal head impaction into the maternal pelvis and prolonged second stage labor.

This result is consistent with previous studies [1,7], which notice that delivery by $\mathrm{CS}$ at full dilatation has been shown to result in more admissions to SCBU due to reduced Apgar score and umbilical artery $\mathrm{pH}$ compared with babies born by successful operative vaginal delivery or 1st C/S (11\% of 209 deliveries versus $6 \%$ of 184 deliveries respectively; adjusted OR 2.64 , 95\% CI $1.16-$ 6.02) [10]. 
More over babies born by CS at full dilatation are 1.5 times more likely to have perinatal asphyxia than those born by CS during the first stage of labor $(11 \%$ of 549 deliveries versus $8 \%$ of 1074 deliveries; 95\% CI 1.06-2.14, P < 0.05) [4]. However, this is likely to be a result of increasing fetal compromise with prolonged duration of delivery, not a result of the procedure. Therefore, it came as no surprise when we found that our current study agrees with literature and showed that $36(18.0 \%)$ of neonates were admitted to the nursery, 11 (5.5\%) of neonates had Low 5 min Apgar score.

Overall pregnancy outcomes in $2^{\text {nd }}$ stage $\mathrm{C} / \mathrm{S}$ were significantly poor due to that all women with $2^{\text {nd }}$ stage $\mathrm{C} / \mathrm{S}$ delayed in labor making surgical interventions inevitable because of fetal distress, FTP and prolonged labor. The higher incidence of intra operative and postoperative complications in this study among women $2^{\text {nd }}$ stage $\mathrm{C} / \mathrm{S}$ are factors that lead to poor outcomes in the mothers and the infants.

Limitation of our study is that, long-term psychological and physical maternal morbidity were not evaluated well. Further studies should be done with proper involvement of long-term psychological and physical maternal morbidity. Another limitation was that the study was used small sample size. Patient selection, sampling, intervention and data collection all done by the same observer.

\section{Conclusion}

Our finding demonstrates positive correlation between increase maternal, fetal morbidity and $2^{\text {nd }}$ stage $\mathrm{C} / \mathrm{S}$. Intra operative bleeding, adhesion, bladder injury, caesarian hysterectomy, perinatal asphyxia, FSB, birth trauma, NICU admission, low Apgar score and postoperative bleeding were most morbidity related to $2^{\text {nd }}$ stage cesarean delivery.

\section{Acknowledgement}

None.

\section{Conflict of Interest}

No Conflict of Interest.

\section{References}

1. Royal college of obstetricians and gynecologists (2001) RCOG clinical effectiveness support unit. The national sentinel cesarean section audit report. London.

2. Fasubaa OB, Ezechi OC, Orji EO, Ogunniyi SO, Akindele ST, et al. (2002) Delivery of the impacted head of the fetus at caesarean section after prolonged obstructed labour: a randomised comparative study of two methods J Obstet Gynecol22(4): 375-378.

3. Cebekulu L, Buchmann EJ (2006) Complications associated with cesarean section in the second stage of labor. Int J Gynaecol Obstet 95(2): 110-114

4. Allen VM, O'Connell CM, Baskett TF (2005) Maternal and perinatal morbidity of caesarean delivery at full cervical dilatation compared with caesarean delivery in the first stage of labor. BJOG 112(7): 986-990.

5. Alexander JM, Leveno KJ, Rouse DJ, Landon MB, Gilbert S 2007) Comparison of maternal and infant outcomes from primary cesarean delivery during the second compared with first stage of labor. Obstet Gynecol 109(4): 917-921.

6. Burrows LJ, Meyn LA, Weber AM (2004) Maternal morbidity associated with vaginal versus caesarean delivery. Obstet Gynecol 103 (5 Pt 1): 907-912.

7. Allen VM, O'Connell CM, Baskett TF (2006) Maternal morbidity associated with caesarean delivery without labor compared with induction of labour at term. Obstet Gynecol 108: 286-294

8. Rabiu KA, Adewunmi AA, Akinola OI, Eti AE, Tayo AO (2011) Comparison of maternal and neonatal outcomes following caesarean section in second versus first stage of labor in a tertiary hospital in Nigeria. Nigerian Postgraduate Medical Journal 18: 165-171.

9. Selo-Ojeme D, Sathiyathasan S, Fayyaz M (2008) Caesarean delivery at full cervical dilatation versus caesarean delivery in the first stage of labour: comparison of maternal and perinatal morbidity. Arch Gynecol Obstet 278(3): 245-249.

10. Murphy DJ, Liebling RE, Verity L, Swingler R, Patel R (2001) Early maternal and neonatal morbidity associated with operative delivery in second stage of labor: a cohort study. Lancet 358: 1203-1207. 